\title{
Prototype Development of Heartbeat and Body Temperature Monitoring System Based on Internet of Things
}

\author{
Ahmad Taqwa ${ }^{1}$ Ade Silvia Handayani ${ }^{1,{ }^{*}}$ Arsyiil Shiddik ${ }^{1}$ Carlos R Sitompul ${ }^{1}$ \\ Yohandri Bow ${ }^{2}$ Nyayu Latifah Husni ${ }^{1}$ Zakaria $^{3}$ \\ ${ }^{I}$ Electrical Engineering Department, Politeknik Negeri Sriwijaya \\ ${ }^{2}$ Chemical Engineering Department, Politeknik Negeri Sriwijaya \\ ${ }^{3}$ English Departement, Politeknik Negeri Sriwijaya \\ *Corresponding author. Email: ade_silvia@polsri.ac.id
}

\begin{abstract}
This paper presents IoT-based health care technology in monitoring vital signs in health services. The result designate prototype to detect health parameters is effectiveness for provide real time online information such as heart rate and body temperature This monitoring system is made using the raspberry pi to process sensors for each parameter. The sensor used to detecting heartbeat is pulse sensor and sensor used to detecting body temperature is DS18B20. The heartbeat and body temperature monitoring system will be connected to node-red as an internet of things platform. Node-red will be displaying the data on the webpage and send the patient information to the medical worker's email. Then the medical worker can monitor patient condition directly.
\end{abstract}

Keywords: Prototype, IoT, healthcare

\section{INTRODUCTION}

In human life, health is the most important things, because by having a healthy body, it will decrease the possibility of getting various kinds of diseases [1]. There are so many healthy lifestyles to get a prime body condition [2], for example eating regularly, taking vitamins, exercising and many others.

The cause of an illness is because someone is too late to know the symptoms [3]. Nowadays, there are so many hospitals who provide medical check-up [4], but it's still not efficient because of the costs is expensive, inadequate tools or the hospital is too far from home. To these problems, technology development is the solution [5].

According to WHO data, around $50 \%$ of the 12 million people die from heart and blood vessel disease [6]. The disease can be handled if someone routinely checks their body's conditions and do a healthy lifestyle. Therefore, a prototype that can be used routinely but still monitored by health workers such as midwives or nurses is needed.

There are so many types of health monitoring prototype that have been made using current technological developments. Health monitoring prototype detect several health parameters with a variety of different technologies for it used, such as in paper by Zulkifli [7], implementing a heart rate sensor using the ZigBee method, applied in sports training. However, this monitoring system not efficient because the sensors are not needed for non-athletes. Prasad Kumari [8] made a heart rate monitoring system using the Bluetooth connection, but this system only has one measure and the output is only displayed on the LCD and not integrated directly to health workers.

In this paper, a health monitoring system will be made with vital organs as the parameters, namely heart rate and body temperature based on the internet of things. Making this prototype is expected to solve problems such as costs, distance to do medical check-ups and the level of human laziness.

The design of the prototype consists of 2 parameters. The prototype designed of a pulse sensor for monitoring heart rate and a DS18B20 sensor for monitoring body temperature. To connect both of sensors, the data processing will be taken by the raspberry pi. After the data captured, raspberry pi will send the information to the node-red webpage and the patient information will be submitted to medical worker's email. 


\section{INTERNET OF THINGS FOR HEALTH MONITORING}

The Internet of Things is a concept where certain objects can transfer data over a network without interaction from human to human or from human to computer devices [9]. People today consider the Internet of things as something big because the internet of things can always be developed. In the industrial, to give information about the condition, equipment design is needed. While using this system, the user can check the equipment easily. With the ease of monitoring can avoid undesirable situations such as the machine does not work because too late to do maintenance.

Many of the devices are using the Internet of things technology, such as in [10-12], as well as a tool for health monitoring. The use of the internet of things for health monitoring can make it easier for officers to get information from patients. Use of the Internet of things in the medical world holds a very important role in quality patient care. due to the increasing variety of patients, a health observation is needed by using patient health information to avoid preventable deaths.

The use of the internet of things for health monitoring has previously been carried out in other studies, wherein the study uses different methods and technologies. In research by Himadri [13], the prototype uses the internet of things to detect information about heart rate and blood pressure of patients by providing alerts through the internet. In research by Narendra [14], the prototype uses the internet of things to send information about body temperature and blood pressure data through the MQTT protocol for web servers.

Table 1. Similar Research

\begin{tabular}{|c|c|c|c|c|c|c|c|}
\hline No & Display & Software & Sensor & Placement & Technology & Parameter(s) & Ref \\
\hline 1 & Computer & Website & $\begin{array}{l}\text { MAX30100, IR } \\
\text { Thermometer, } \\
\text { Wrist BP module }\end{array}$ & Wrist & $\begin{array}{l}\text { ZigBee } \\
\text { GPRS }\end{array}$ & $\begin{array}{l}\text { Blood Pressure, } \\
\text { Heartbeat, } \\
\text { Temperature }\end{array}$ & {$[15]$} \\
\hline 2 & $\begin{array}{l}\text { Computer, } \\
\text { Android }\end{array}$ & Java & $\begin{array}{l}\text { Echocardiograph } \\
\text { (ECG) }\end{array}$ & Wrist & $\begin{array}{l}\text { Cloud } \\
\text { Prosessing } \\
\text { WSN }\end{array}$ & Heartbeat, Oxy & [16] \\
\hline 3 & $\begin{array}{l}\text { Android } \\
\text { Computer }\end{array}$ & $\begin{array}{c}\text { Java } \\
\text { Website }\end{array}$ & $\begin{array}{l}\text { Accelerometer, } \\
\text { ECG, gyroscope }\end{array}$ & Wrist & $\begin{array}{l}\text { WSN } \\
\text { Cloud }\end{array}$ & Heartbeat, Oxy & [17] \\
\hline 4 & Komputer & $\begin{array}{c}\text { One } \\
\text { System } \\
\text { GUI }\end{array}$ & $\begin{array}{c}\text { Phototransistor, } \\
\text { Infrared, ADXL } \\
\text { Accelerometer, } \\
\text { LM35 }\end{array}$ & $\begin{array}{l}\text { Wrist } \\
\text { Finger }\end{array}$ & XBee & $\begin{array}{l}\text { Heartbeat, } \\
\text { Temperature }\end{array}$ & [18] \\
\hline 5 & $\begin{array}{l}\text { Smart } \\
\text { Phone } \\
\text { Backend } \\
\text { Server }\end{array}$ & & MAX30100 & Finger & $\begin{array}{l}\text { Cloud } \\
\text { Service }\end{array}$ & Oxy, Heartbeat & [19] \\
\hline 6 & Komputer & MGUI & MAX30100 & Finger & $\begin{array}{l}\text { MCU } \\
\text { Operation }\end{array}$ & Heartbeat, Oxy & [20] \\
\hline 7 & $\begin{array}{c}\text { Smart } \\
\text { Phone } \\
\text { Komputer }\end{array}$ & $\begin{array}{l}\text { Website } \\
\text { Java }\end{array}$ & $\begin{array}{l}\text { ECG Sensor } \\
\text { PPG Sensor } \\
\text { Accelerometer } \\
\text { Gyroscope }\end{array}$ & $\begin{array}{l}\text { Knee, Wrist, } \\
\text { Chest, } \\
\text { Finger }\end{array}$ & ZigBee & $\begin{array}{l}\text { Heartbeat, Knee } \\
\text { Movement, } \\
\text { Oxy, } \\
\text { Temperature }\end{array}$ & [21] \\
\hline 8 & $\begin{array}{c}\text { Smart } \\
\text { Phone } \\
\text { Komputer }\end{array}$ & $\begin{array}{l}\text { IMEC } \\
\text { Monitori } \\
\text { ng } \\
\text { System }\end{array}$ & ECG Sensor & $\begin{array}{c}\text { Ankle, } \\
\text { Wrist, Chest }\end{array}$ & Wireless & $\begin{array}{l}\text { Heartbeat, } \\
\text { Motion Sensor, } \\
\text { Respiratory }\end{array}$ & [22] \\
\hline 9 & $\begin{array}{l}\text { Komputer, } \\
\text { Smart } \\
\text { Phone }\end{array}$ & $\begin{array}{c}\text { Java } \\
\text { Web } \\
\text { Server }\end{array}$ & ECG Sensor & Wrist & $\begin{array}{l}\text { Cloud- } \\
\text { Assisted }\end{array}$ & Heartbeat & {$[23]$} \\
\hline
\end{tabular}

Table 1 provides a list of similar studies on health monitoring systems. these studies have their respective advantages and the technology used also varies so that it can be a reference in designing this health monitoring system. 


\section{TECHNOLOGY FOR DEVICE}

In this prototype development, it takes some of the technology for designing the hardware and software. The technology used in this device has various features and functions to carry out its own role. In software development, the technology used is node - red application that already installed on raspberry pi 3 so that the design of this software will be more flexible by adjusting the sensor's performance. Software designed using node-red is a web page display and connected using the IP address of the raspberry pi 3 . Whereas in hardware design, there are main components which are the main technology of this monitoring system, it can be seen in table 2 .

Table 2. Device's Component

\begin{tabular}{|c|c|c|c|}
\hline No & Name & Feature & Function \\
\hline 1 & Raspberry Pi 3 & $\begin{array}{l}\text { - SoC: Broadcom BCM2837 } \\
\text { - CPU: 4× ARM Cortex-A53, 1.2GHz } \\
\text { - GPU: Broadcom VideoCore IV } \\
\text { - RAM: } 1 \text { GB LPDDR2 (900 MHz) } \\
\text { - Networking: 10/100 Ethernet, } \\
\text { 2.4GHz 802.11n wireless } \\
\text { - Bluetooth: Bluetooth } 4.1 \text { Classic, } \\
\text { Bluetooth Low Energy } \\
\text { - Storage: microSD } \\
\text { - GPIO: 40-pin header, populated } \\
\text { - Ports: HDMI, 3.5mm analogue } \\
\text { audio-video jack, 4× USB 2.0, } \\
\text { Ethernet, Camera Serial Interface } \\
\text { (CSI), Display Serial Interface (DSI) }\end{array}$ & $\begin{array}{l}\text { Process the sensors using python } \\
\text { programming language }\end{array}$ \\
\hline 2 & Pulse Sensor & $\begin{array}{l}\text { - Biometric Pulse Rate or Heart } \\
\text { - Rate detecting sensor. } \\
\text { - Plug and Play type sensor. } \\
\text { - Operating Voltage: }+5 \mathrm{~V} \text { or }+3.3 \mathrm{~V} \text {. } \\
\text { - Current Consumption: } 4 \mathrm{~mA} \text {. } \\
\text { - Inbuilt Amplification and } \\
\text { - Noise cancellation circuit. } \\
\text { - Diameter: } 0.625 " \\
\text { - Thickness: } 0.125 " \text { Thick. }\end{array}$ & $\begin{array}{l}\text { Sensor for detecting the heartbeat, this } \\
\text { sensor is analog sensor and will be } \\
\text { convert to digital data using IC } \\
\text { MCP3008. }\end{array}$ \\
\hline 3 & DS18B20 & $\begin{array}{l}\text { - Programmable Digital Temperature } \\
\text { - Sensor } \\
\text { - Communicates using } 1 \text {-Wire method } \\
\text { - Operating voltage: } 3 \mathrm{~V} \text { to } 5 \mathrm{~V} \\
\text { - Temperature Range: }-55^{\circ} \mathrm{C} \text { to } \\
+125^{\circ} \mathrm{C} \\
\text { - Accuracy: } \pm 0.5^{\circ} \mathrm{C} \\
\text { - Output Resolution: } 9 \text {-bit to } 12 \text {-bit } \\
\text { (programmable) } \\
\text { - Unique } 64-b i t \text { address enables } \\
\text { multiplexing } \\
\text { - Conversion time: } 750 \mathrm{~ms} \text { at } 12 \text {-bit } \\
\text { - Programmable alarm options } \\
\text { - Available as To- } 92, \mathrm{SOP} \text { and even as } \\
\text { a waterproof sensor }\end{array}$ & $\begin{array}{l}\text { Sensor for detecting the body } \\
\text { temperature, this sensor is digital } \\
\text { sensor so it can directly programable } \\
\text { using raspberry pi. }\end{array}$ \\
\hline 4 & IC MCP3008 & $\begin{array}{l}\text { - } 8 \text {-Channel 10-bit ADC IC } \\
\text { - Communication protocol: Serial SPI } \\
\text { interface } \\
\text { - Operating voltage } 2.7 \mathrm{~V} \text { to } 5 \mathrm{~V} \\
\text { - ADC method: Successive } \\
\text { Approximation (SAR) }\end{array}$ & $\begin{array}{l}\text { Analog }- \text { to }- \text { Digital Converter to } \\
\text { convert pulse sensor. }\end{array}$ \\
\hline
\end{tabular}


- Sampling Rate: 200ksps and 75ksps for $5 \mathrm{~V}$ and $2.7 \mathrm{~V}$ resp.

- Available in 16-pin PDIP, and SOIC packages

\section{DESIGN OF HEARTBEAT AND BODY TEMPERATURE MONITORING SYSTEM BASED ON INTERNET OF THINGS}

In this monitoring system, some method is used for each part. The method used in data retrieval is by attaching body parts to sensors, such as fingers for heart rate sensors and armpits for body temperature sensors and patient body health data will be processed for display. The node arrangement method is used to create the desired interface according to the needs and system of the designed device. This node arrangement is used by understanding the functions of each node. Meanwhile, the comparison method is used to compare the monitoring system that has been designed with medical equipment that is already available such as a market thermometer and existing applications to get the accuracy of the instrument.

\subsection{Hardware Design}

In designing this hardware, Raspberry Pi $5 \mathrm{~V}$ power and a minimum of $700 \mathrm{~mA}$ of current. Meanwhile, the sensors used to measure health parameters are pulse sensors for heart rate and DS18B20 sensors for body temperature.

Pulse sensors work by using the properties of hemoglobin that can absorb light and natural pulses. Meanwhile, the DS18B20 sensor will convert the output voltage into temperature with a simple conversion factor. Input from the pulse sensor and DS18B20 will be connected to the Raspberry Pi using the GPIO pin on the Raspberry Pi so that the data from the sensor can be processed by the Raspberry Pi. The Wifi module that is already on the Raspberry Pi will send the results of monitoring to the web in the form of numbers.

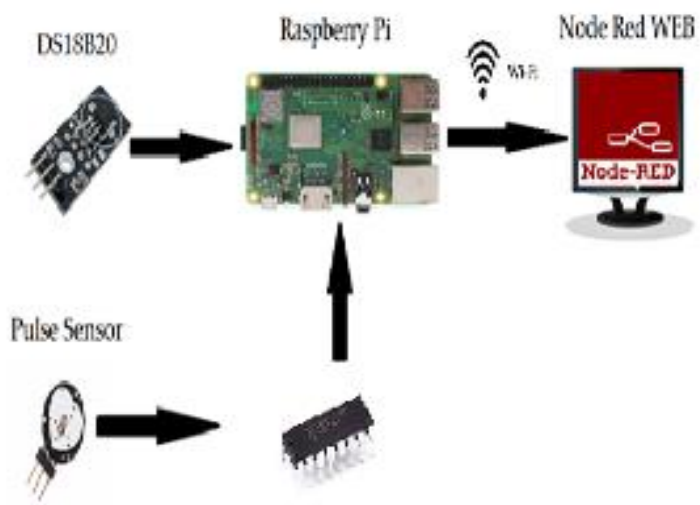

\subsection{Node-Red Program}

The node - red program is used in designing the web page. It created by connecting each node for the program and the output of the display. It's connected automatically to the private website of the raspberry pi.

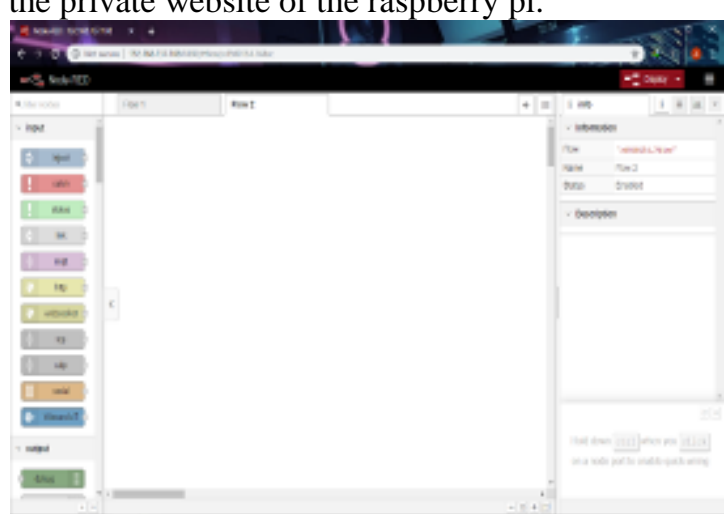

Figure 2. Node-Red Program Display

Figure 2 is the display of the node - red program. The node - red program will run after the raspberry pi service starts. To activate it manually, you can use the Node-Red - Start command and to end it manually can call the Node - Red - Stop command. To display data, we need to arrange the nodes used for sensors and displays inflow.

\subsection{Data Displaying in Terminal Interface}

The data's appearance from the program's interface consists of 2, namely by using the raspberry pi terminal and using a shell from Python. First, the patient or respondent who will check body temperature only needs to put the sensor on the body, but for the most exact condition is in the armpit, forehead or inside the patient's mouth, the data is displaying on the raspberry pi terminal as shown in Figure 2.

Figure 1. Hardware Design 


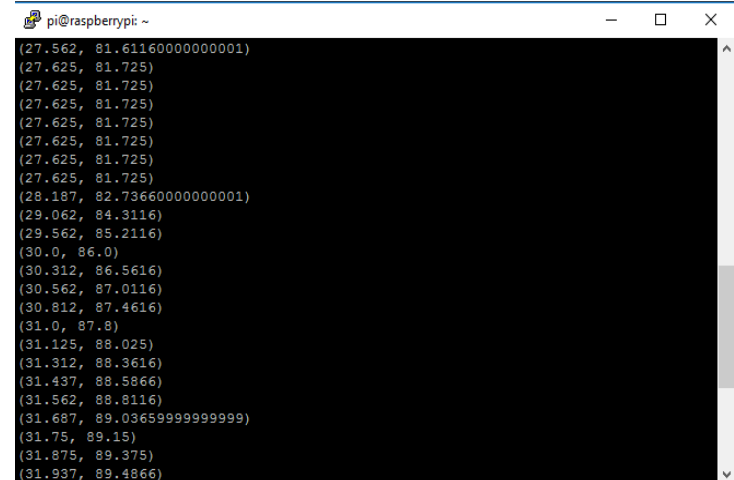

Figure 3. Temperature Data

Meanwhile, for monitoring heart rate with a pulse sensor, we only need to put the finger on the front side of the sensor, then the data is displaying through the python shell as shown in figure 4

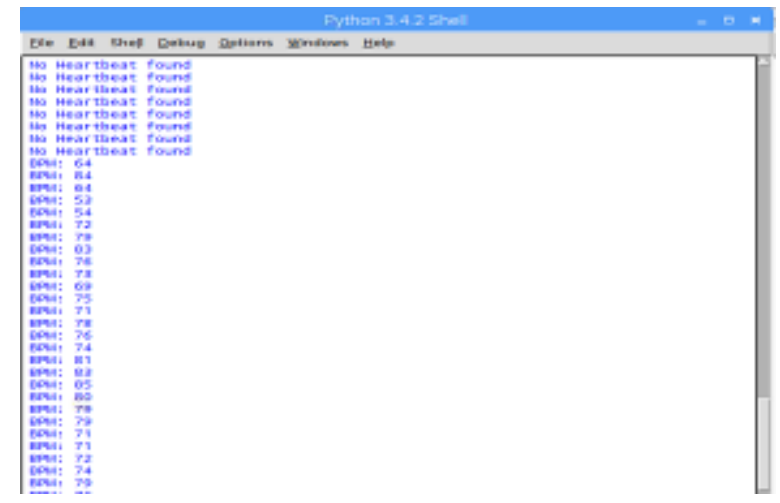

Figure 4. Heartbeat Data from Python Shell

\subsection{Data Display On Node-Red Web Page}

With the rapid development of technology, a very flexible tool is needed depending on needs. So, the use of node-red is the right choice because it is flexible and directly integrates to the raspberry pi. This development method has staged such as (1) retrieving data from the sensor, (2) connecting the sensor nodes in question, (3) displaying the data.

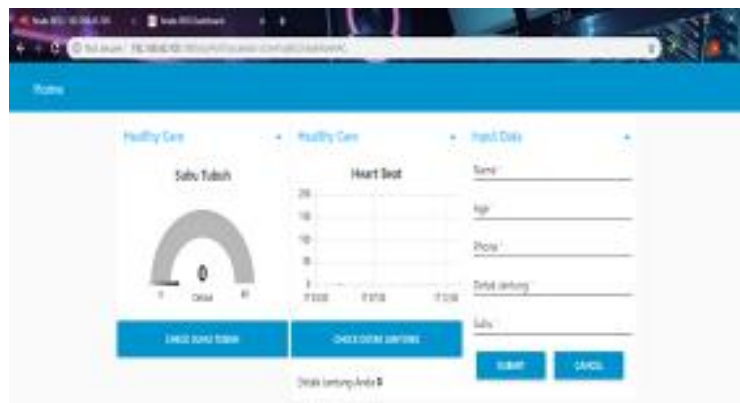

Figure 5. Node-Red Web Page Display

Figure 5 is the display of a node-red web page where all data from the sensor will be displayed. There are several indicators in that display, temperature, heartbeat, and form to input the data. In that display, the sensor will be active after the button clicked. The data will be input after the submit button clicked then it will send the results to email.

\subsection{Performance of Monitoring System}

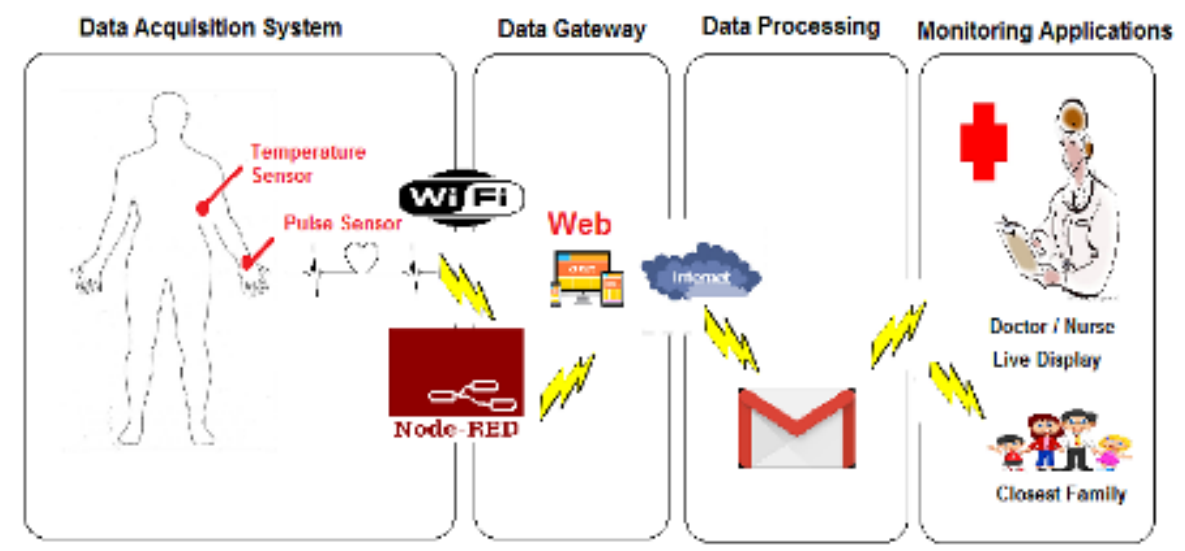

Figure. 6. Performance of Monitoring System

In the heartbeat and temperature monitoring system that was made, the sensor will retrieve data from the patient's body part for the temperature sensor and finger or wrist to the heart rate sensor. After sensors take the data from the body, raspberry pi will process the data of the monitoring system. The Raspberry pi will send results to the node-red which is using the IP of the SSID connection. The patient can see the monitoring data by opening the webpage by entering the connected IP address of Raspberry Pi, namely 192.168.43.105. After getting the results of monitoring, the patient can input data by entering personal data in the column provided, which later node-red will send the data to the email of the medical officer. 


\section{RESULT AND DISCUSSION}

\subsection{Heartbeat and Temperature Monitoring System Result}

The results of designing device health monitoring are divided into two parts, the results of hardware design and software design using the node-red. This system is intended for home patients who need health monitoring with parameters of heart rate and body temperature. This system has been tested on several respondents.

The overall system performance in this test is by providing data through the body by attaching body parts to the sensor, then the system will respond to the data obtained by the sensor for processing raspberry pi so that it can send the data on the internet of things platform, node-red.

\subsection{Hardware Design Results for Heartbeat and Temperature Monitoring Systems}

The hardware design of the health monitoring system was made using raspberry pi 3 which combined the DB18B20 pulse sensor and sensor.

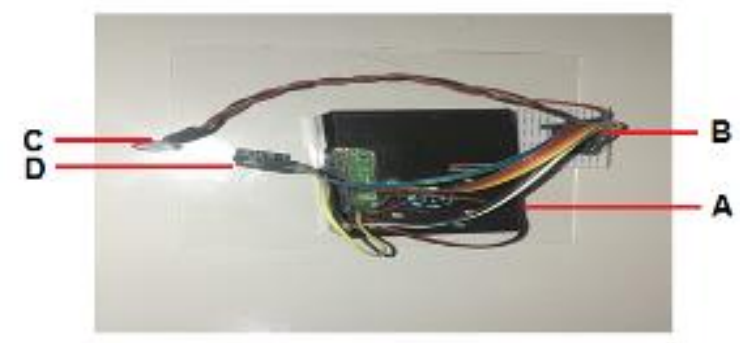

Figure 7. Hardware Design of Health Monitoring System

In figure 7 is the display of the hardware health monitoring system. In the picture above there are several hardware components including:

- A Is a Raspberry Pi as the main processing unit

- B Is an MCP3008 as an ADC to process analog sensors so that they can be read by the Raspberry Pi.

- $\mathrm{C}$ is a Pulse Sensor as a heart rate sensor

- $\mathrm{D}$ is a DS18B20 sensor as a body temperature sensor

\subsection{Software Design Result}

From the tests that have been carried out, the hardware of the monitoring system is integrated with the internet of things node - red platform in the form of a webpage. The program is run by using node-red as the viewer of the results of the health monitoring system on the web display. In the node-red program, several nodes will connect each other so that the results of the sensors can be displayed as shown in Figure 8.

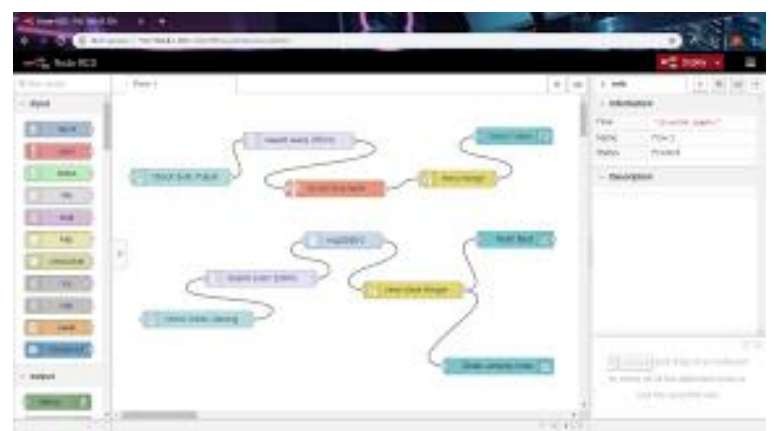

Figure. 8 Node-Red Web Design

Figure 8 is a display of node-red before the application running, there are nodes for each parameter. First, there is a node from the sensor DS18b20 to read the temperature sensor from raspberry pi's gpio, then there is a node from the ADC MCP3008 which has converted the analog data belonging to the pulse sensor, then will offer the data on the raspberry pi gpio pin. Then the nodes of the sensor are connected to nodes from the dashboard such as gauges and charts so that the node red web page can display the monitoring results.

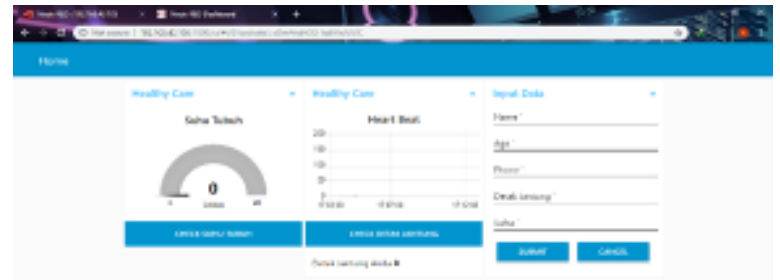

Figure. 9 Node-Red Web Interface

Figure 9 is the web display of the node - red before the monitoring system running, to run the monitoring system, click the existing button on the web page, to monitor body temperature, click the "Body Temperature Check" button, and to monitor heart rate, click the "Check Heartbeat button". After that, the data will automatically measure the desired parameters. After obtaining data from the results of monitoring, patients are expected to be able to send data through input manually in the column provided, the inputted data will be automatically sent to the email so that it can be monitored by the health workers.

\subsection{Test Result}

The test was conducted with 5 respondents to test heart rate and body temperature. 5 respondents involved in the testing are patients with different ages and conditions can be seen in table 1 . 
Table 3. Body Temperature Monitoring Result

\begin{tabular}{|c|c|c|c|c|}
\hline $\mathbf{5}$ & \multicolumn{5}{|l|}{} \\
\hline $\mathbf{7}$ & Normal & $36.2^{\circ} \mathrm{C}$ & $36.6^{\circ} \mathrm{C}$ & 1.09 \\
\hline $\mathbf{1 9}$ & Normal & $36.1^{\circ} \mathrm{C}$ & $36.3^{\circ} \mathrm{C}$ & 0.5 \\
\hline $\mathbf{2 2}$ & Normal & $36.3^{\circ} \mathrm{C}$ & $36.3^{\circ} \mathrm{C}$ & 0 \\
\hline $\mathbf{2 4}$ & Demam & $37.7^{\circ} \mathrm{C}$ & $37.4^{\circ} \mathrm{C}$ & 0.267 \\
\hline $\mathbf{5 4}$ & Fever & $37.1^{\circ} \mathrm{C}$ & $37.2^{\circ} \mathrm{C}$ & 0.267 \\
\hline
\end{tabular}

In Table 1, the results of the comparison of body temperatures were obtained using a manual thermometer with a device that has made using a DS18B20 sensor. Testing is done by considering age and condition. The sensor's place is carried out on the armpit so that the temperature obtained is quite accurate.

In these results, it was found that the differences between the two devices were quite low and the measurement results could be said to be almost the same. There are 2 types of conditions, normal conditions and fever. For normal conditions, the temperature obtained for both thermometers is less than the normal limit, where the normal temperature in the axilla is about $34.7^{\circ} \mathrm{C}-37.3^{\circ} \mathrm{C}$, while temperatures below $34.7^{\circ} \mathrm{C}$ are symptoms from hypothermia and temperatures above $37.3^{\circ} \mathrm{C}$ are symptoms of fever

Table 4. Heart Rate Monitoring Result

\begin{tabular}{|c|c|c|c|c|}
\hline \multicolumn{5}{|l|}{} \\
\hline $\mathbf{7}$ & Rest & 74 BPM & 69 BPM & 6.75 \\
\hline $\mathbf{1 9}$ & Rest & 76 BPM & 72 BPM & 5.26 \\
\hline $\mathbf{2 2}$ & Sport & 132 BPM & 138 & 4.34 \\
& & & BPM & \\
\hline $\mathbf{2 4}$ & Rest & 83 BPM & 86 BPM & 3.48 \\
\hline $\mathbf{5 4}$ & Rest & 79 BPM & 83 BPM & 4.81 \\
\hline
\end{tabular}

In table 2, the system monitoring has been tested based on the age and condition of 5 respondents. The test is done by comparing the measurement results between a heart rate detection application in the play store and heart rate detected.

The results of the tests carried out with applications and tools made using pulse sensors have differences that are not too large and are still within the scope of the threshold. Can be seen in the test results that the condition of the resting heartbeat obtained ranges from $60-90$ BPM and for strenuous activities such as exercise, a normal heart rate is 125 - 150 BPM. Data from the interface test tool with the application can be seen in the table.

\subsection{Input Data Results to Email}

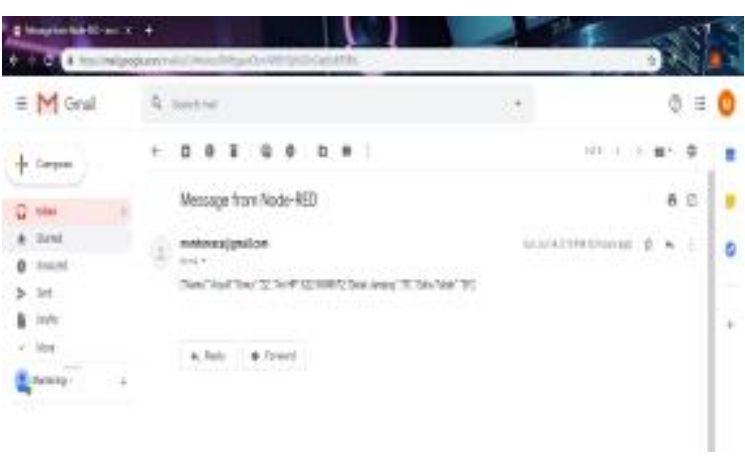

Figure 8. Email to Interface

Figure 8. is the test result of sending data from node-red to email. The e-mail is authorized to health workers, then the health workers will monitor patient data. The patient should input data at the form at the web page manually, so it can avoid the spam of continuous measurement.

\section{CONCLUSIONS}

In the design of this health monitoring system, the device is made by integrating hardware and software. The hardware uses the raspberry pi as the main processor to process the pulse sensor as a heart rate sensor and the DS18B20 sensor as a body temperature sensor. Meanwhile, the software is designed using the node-red application as a platform for the internet of things by connecting the nodes obtained from the hardware so that it can be connected to each other in the output node-red in the form of a web page. The web page design has a patient data form so that patients can send monitoring data directly to the health worker's email.

\section{REFERENCES}

[1] S. Sugawara, "Clinical evaluation of a nonsteroid anti-inflammatory drug zaltoprofen 40 mg tablets on lumbago," Japanese Pharmacol. Ther., vol. 23, no. 5, pp. 323-335, 1995.

[2] Rizki Hananta, "Pola Hidup Sehat" pp. 1-10, 2010.

[3] A. B. Mutiara, A.Muslim, A. L. Prihatin, A. Suhendra, and T. Oswari, "Pengembangan E Anamnesis Berdasarkan Sympthom Pengembangan E - Anamnesis," vol. 10, no. March 2016, p. 64, 2014.

[4] D. Firmanda, "Clinical Pathways Kesehatan Anak," Sari Pediatr., vol. 8, no. 3, p. 195, 2016.

[5] W. Wardiana, "Perkembangan Teknologi Informasi di Indonesia," Eur. Arch. Psychiatry Clin. Neurosci., vol. 243, no. 5, pp. 224-228, 1994.

[6] Depkes, "Sistem Kesehatan Nasional, Perpres 72/2012," Jurnal, vol. 45, pp. 22-29, 2009. 
[7] N. S. A. Zulkifli, F. K. Che Harun, and N. S. Azahar, "XBee wireless sensor networks for Heart Rate Monitoring in sport training," 2012 Int. Conf. Biomed. Eng. ICoBE 2012, no. in C, pp. 441-444, 2012.

[8] P. K. Nisha and Y. Vinita, "Heart Rate Monitoring and Data Transmission via Bluetooth," Int. J. Innov. Emerg. Res. Eng., vol. 2, no. 2, pp. 99-105, 2015.

[9] Rajkumar, S., Srikanth, M., \& Ramasubramanian, N. (2018). Health monitoring system using Raspberry PI. 2017 International Conference on Big Data, IoT and Data Science, BID 2017, 2018-Janua, 116119.

[10] Latifah, N.H., Sitangsu, S., Rasyad, S. and Handayani, A.S., 2020. Real Time Garbage Bin Capacity Monitoring. Computer Engineering and Applications Journal,9(2), pp.127-134.

[11] N. L. Husni, Robi, E. Prihatini, Nurhaida, A. Silvia and Firdaus, "Garbage Monitoring and Warning System," 2019 International Conference on Electrical Engineering and Computer Science (ICECOS), Batam Island, Indonesia, 2019, pp. 171-175.

[12] A. S. Handayani, N. L. Husni, R. Permatasari and C. R. Sitompul, "Implementation of Multi Sensor Network as Air Monitoring Using IoT Applications," 2019 34th International Technical Conference on Circuits/Systems, Computers and Communications (ITC-CSCC), JeJu, Korea (South), 2019, pp. 1-4.

[13] Saha, H. N., Auddy, S., Pal, S., Kumar, S., Pandey, S., \& Singh, R. (2017). Health Monitoring using Internet of Things ( IoT ), (March 2018).

[14] Swaroop, K. N., Chandu, K., Gorrepotu, R., \& Deb, S. (2019). Internet of Things A health monitoring system for vital signs using IoT. Internet of Things, 5, 116-129.

[15] M. H. Riaz, U. Rashid, M. Ali, and L. Li, "Internet of things based wireless patient body area monitoring network," Proc. - 2017 IEEE Int. Conf. Internet Things, IEEE Green Comput. Commun. IEEE Cyber, Phys. Soc.
Comput. IEEE Smart Data, iThingsGreenCom-CPSCom-SmartData 2017, vol 2018-January, pp. 970-973, 2018.

[16] M. Hassanalieragh et al., "Health Monitoring and Management Using Internet-of-Things (IoT) Sensing with Cloud-Based Processing: Opportunities and Challenges," Proc. - 2015 IEEE Int. Conf. Serv. Comput. SCC 2015, pp. 285-292, 2015

[17] P. Puspitaningayu, A. Widodo, and E. Yundra, "Wireless Body Area Network s dan Pengaruhnya dalam Perkembangan Teknologi m-Health," Tidak Terdaftar, vol. 01, pp. 2430, 2018.

[18] K. Malhi, S. C. Mukhopadhyay, J. Schnepper, M. Haefke, and H. Ewald, "A zigbee-based wearable physiological parameters monitoring system," IEEE Sens. J., vol. 12, no. 3, pp. 423 430, 2012.

[19] S. Rajkumar, M. Srikanth, and N. Ramasubramanian, "Health monitoring system using Raspberry PI," 2017 Int. Conf. Big Data, IoT Data Sci. BID 2017, vol. 2018-Janua, pp. 116-119, 2018.

[20] E. Jovanov, V. R. Nallathimmareddygari, and J. E. Pryor, "SmartStuff: A case study of a smart water bottle," Proc. Annu. Int. Conf. IEEE Eng. Med. Biol. Soc. EMBS, vol. 2016Octob, pp. 6307-6310, 2016.

[21] E. M. G. Rodrigues, R. Godina, C. M. P. Cabrita, and J. P. S. Catalão, "Experimental low cost reflective type oximeter for wearable health systems," Biomed. Signal Process. Control, vol. 31, pp. 419-433, 2017.

[22] S. Majumder, T. Mondal, and M. J. Deen, "Wearable sensors for remote health monitoring," Sensors (Switzerland), vol. 17, no. 1, 2017.

[23] S. Patel, H. Park, P. Bonato, L. Chan, and M. Rodgers, "A review of wearable sensors and systems with application in rehabilitation," J. Neuroeng. Rehabil., vol. 9, no. 1, p. 21, 2012. 